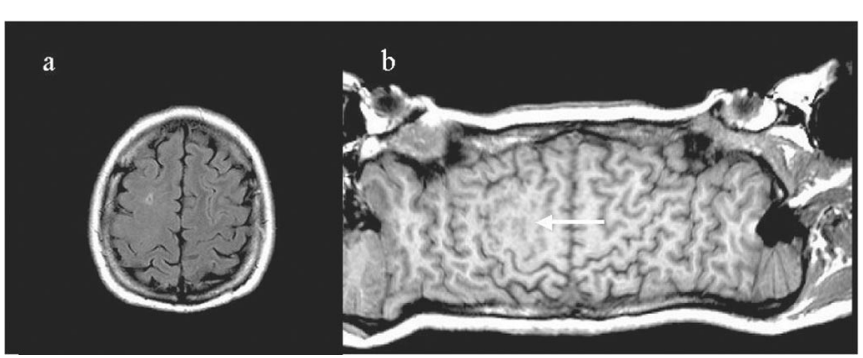

Figure 1. A 5-mm-thick axial fluid-attenuated inversion recovery MRI shows homogenous lesion in the right frontal lobe (a), while planar brain surface reformatted MRI demonstrates focal polymicrogyria (b: arrow).

\section{Focal polymicrogyria: Planar-surface MRI}

H. Urbach, MD, A. Perez-Bouza, $M D$

J. von Oertzen, MD, Bonn, Germany

A 22-year-old woman with drug-resistant complex focal seizures underwent stereotactic biopsy of a frontal lobe lesion, which revealed "gliosis." Epilepsy-dedicated $\mathrm{MRI}^{1}$ with planar brain surface views ${ }^{2}$ reformatted from a sagittal three-dimensional T1weighted gradient echo sequence with $1 \mathrm{~mm}^{3}$ isotropic voxel demonstrated focal polymicrogyria (figure 1). Following subdural grid implantation extended lesionectomy was performed. Two years after surgery the patient had worthwhile seizure improvement (Engel's class IIIa). Correlation of MRI and histopathology explained why 5 -mm-thick MRI slices are suited to display normal

Address correspondence and reprint requests to Dr. Horst Urbach, University of Bonn, Sigmund Freud Str. 25, Bonn, Germany D-53105; e-mail: urbach@uni-bonn.de
Neuro Images

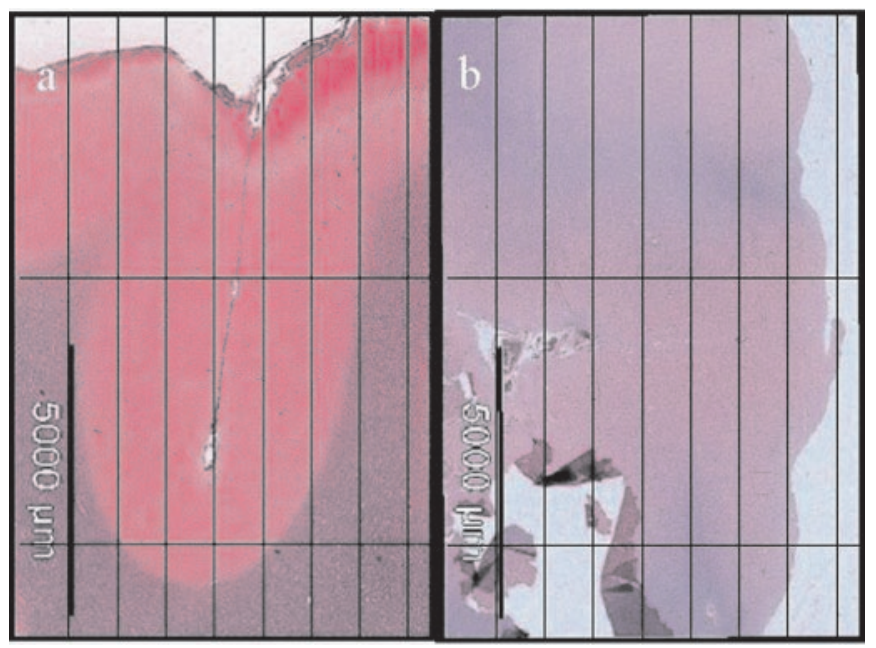

Figure 2. H-E staining of neighboring normal (a) and polymicrogyric cortex (b) with a lattice displaying the imaging matrix of the fluid-attenuated inversion recovery sequence.

cortex but fail to characterize the lesion. If the brain is unfolded along its surface, however, polymicrogyria is clearly visible (figure 2).

1. von Oertzen J, Urbach H, Jungblut S, et al. Standard MRI is inadequate for patients with refractory focal epilepsy. J Neurol Neurosurg Psychiatry 2002;73:643-647.

2. Scheef L, Hoenig K, Urbach H, Schild H, Koenig R. Curved-surface projection. An alternative method for visualizing functional MR imaging results. AJNR Am J Neuroradiol 2003;24:1045-1048. 


\section{Neurology}

\section{Focal polymicrogyria: Planar-surface MRI}

H. Urbach, A. Perez-Bouza and J. von Oertzen

Neurology 2004;62;1227

DOI 10.1212/WNL.62.7.1227

\section{This information is current as of April 12, 2004}

\section{Updated Information \&} Services

References

Permissions \& Licensing

Reprints including high resolution figures, can be found at: http://n.neurology.org/content/62/7/1227.full

This article cites 2 articles, 2 of which you can access for free at: http://n.neurology.org/content/62/7/1227.full\#ref-list-1

Information about reproducing this article in parts (figures,tables) or in its entirety can be found online at:

http://www.neurology.org/about/about_the_journal\#permissions

Information about ordering reprints can be found online: http://n.neurology.org/subscribers/advertise

Neurology ${ }^{\circledR}$ is the official journal of the American Academy of Neurology. Published continuously since 1951, it is now a weekly with 48 issues per year. Copyright. All rights reserved. Print ISSN: 0028-3878. Online ISSN: 1526-632X.

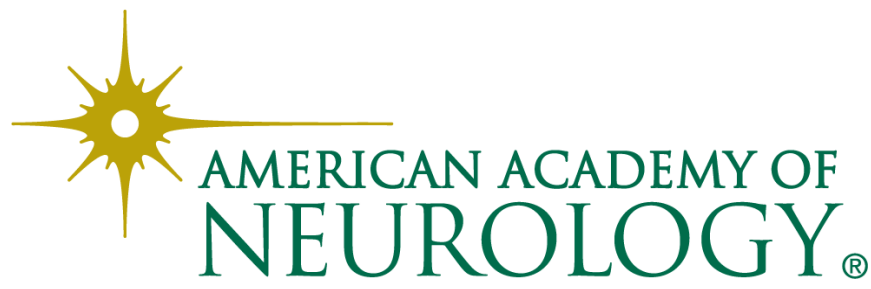

